\title{
UM INIMIGO CHAMADO CORONAVÍRUS/COVID-19: ANÁLISE DE NOTÍCIAS NA PERSPECTIVA DOS MCIS METAFÓRICOS
}

\author{
SÉRGIO RICARDO PEREIRA DE CARVALHO (UFPB) ${ }^{1}$ \\ https://orcid.org/0000-0001-5119-7585 \\ ANDRÉA BEZERRA DOS SANTOS SILVA (UFPB) 2 \\ https://orcid.org/0000-0003-4900-1568 \\ LUIZ HENRIQUE SANTOS DE ANDRADE (IFPB) ${ }^{3}$ \\ https://orcid.org/0000-0001-7104-8739
}

\begin{abstract}
RESUMO: Este artigo se propôs a analisar, através de expressões linguísticas metafóricas, como são categorizados os termos coronavírus/Covid-19, em manchetes de notícias, na perspectiva dos Modelos Cognitivos Idealizados (MCls) metafóricos. Como referencial teórico, utilizamos a Teoria da Metáfora Conceptual aventada por Lakoff e Johnson (2002 [1980]), os Modelos Cognitivos Idealizados de Lakoff (1987) e as contribuições de Feltes (2007). O corpus analisado é constituído de manchetes de notícias extraídas dos sites de dois jornais: Folha de São Paulo e O Globo. É importante destacar que não recorremos ao corpo da notícia, mas às expressões linguísticas atualizadoras que foram extraídas exclusivamente do título que compõe a notícia. Justificamos a relevância deste artigo acadêmico na área da Semântica Cognitiva, uma vez que trazemos novos dados sobre o fenômeno da metáfora conceptual em um tema atual, demonstrando que pensamos e interpretamos os assuntos do dia a dia de maneira metafórica, ao contrário do que pregavam os estudos clássicos. A análise dos dados revelou que a metáfora CORONAVÍRUS/COVID-19 É INIMIGO foi amplamente atualizada por expressões linguísticas para descrever, metaforicamente, várias ações no domínio experiencial GUERRA. Nesse sentido, verificamos que os termos coronavírus/covid-19 foram categorizados metaforicamente como um inimigo em potencial que motiva, discursivamente, o leitor a adotar "estratégias de guerra" como se proteger, combater, conter, enfrentar, etc. Dessa maneira, constatamos, metaforicamente, a criação de um espaço de combate ou luta nas manchetes de notícias analisadas, que sugerem a criação de estratégias para vencer e/ou combater o coronavírus/Covid-19.
\end{abstract}

PALAVRAS-CHAVE: Metáfora conceptual. Coronavírus/Covid-19. Notícia.

ABSTRACT: This article aims to analyze, through metaphorical linguistic expressions, how the terms coronavirus/Covid-19 are categorized, in news headlines, in the metaphorical Idealized Cognitive Models (ICMs) perspective. As theoretical framework, we used the Theory of Conceptual Metaphor proposed by Lakoff and Johnson (2002 [1980]), Idealized Cognitive Models of Lakoff (1987) and Feltes' contributions (2007). The analyzed corpus consists of news headlines extracted from the websites of two news portals: Folha de São Paulo and O Globo. It is important to highlight that we do not use the body of the news, but the updated linguistic expressions that were extracted exclusively from the title that composes the news. We justify the relevance of this academic article in the area of Cognitive Semantics, taking into account that we bring new data on the phenomenon of conceptual metaphor in a current theme/subject, demonstrating that we think and interpret everyday subjects in

\footnotetext{
${ }^{1}$ Mestre em Linguística pelo Programa de Pós-Graduação em Linguística (PROLING) da Universidade Federal da Paraíba e Professor de Língua Portuguesa da rede privada de ensino em João Pessoa. E-mail: sergio.riccardo@hotmail.com

2 Mestranda em Linguística pelo Programa de Pós-Graduação em Linguística (PROLING) da Universidade Federal da Paraíba e Membro do grupo Teorias Linguísticas de Base/TLB.E-mail: andrea.dlcv@hotmai.com

${ }^{3}$ Doutor em Linguística pelo Programa de Pós-Graduação em Linguística (PROLING) da Universidade Federal da Paraíba e Professor EBTT de Língua Inglesa do Instituto Federal de Educação, Ciência e Tecnologia da Paraíba/Campus Catolé do Rocha. E-mail: luizao_andrade2008@hotmail.com
} 


\section{$=$ TRAMA $=$}

a metaphorical way, contrary to what the classical studies preached. Data analysis revealed that the metaphor CORONAVIRUS/COVID-19 IS ENEMY was widely updated by linguistic expressions to describe, metaphorically, various actions in the WAR experiential domain. In this sense, we found that the terms coronavirus/covid-19 were metaphorically categorized as a potential enemy that discursively motivates the reader to adopt "war strategies" such as protecting, fighting, containing, facing, etc. Thus, we verified, metaphorically, the creation of a space for combat or struggle in news headlines, where strategies must be created to win and/or fight the coronavirus/Covid-19.

KEYWORDS: Conceptual Metaphor. Coronavirus/Covid-19. News.

\section{INTRODUÇÃO}

A publicação da obra clássica Metaphors we live by, em 1980, escrita por Lakoff e Johnson, traduzida para a língua portuguesa como Metáforas da vida cotidiana (2002), mudou a visão clássica da metáfora, uma vez que reconheceu seu caráter conceptual e sua presença não somente na linguagem, como também no pensamento e, consequentemente, em nossas experiências cotidianas. Nessa perspectiva, um conceito metafórico consiste de uma estrutura binária resultante da relação que parte de um domínio fonte, conceito mais concreto ou mais diretamente experienciável, de onde são mapeados parcialmente alguns aspectos para um domínio alvo, que compreende os conceitos mais abstratos ou menos diretamente experienciáveis, não havendo, portanto, uma identificação total entre os conceitos metafóricos. Conforme os autores, tal fato pode ser observado na metáfora conceptual DISCUSSÃO É GUERRA 4 , pois nela a discussão, conceito mais abstrato, é estruturado a partir do conceito de guerra, que é mais concreto.

É nessa abordagem, portanto, que buscamos investigar expressões linguísticas que tratam sobre coronavirus/Covid-195, na perspectiva dos MCls metafóricos, circunscritas em notícias veiculadas em dois jornais de circulação nacional: Folha de São Paulo e O Globo.

Nessa esfera discursiva, investigamos a metáfora conceptual CORONAVÍRUS/COVID19 É INIMIGO atualizada por diferentes expressões linguísticas, amplamente utilizadas para descrever, metaforicamente, várias ações no domínio experiencial GUERRA. Nesse sentido, entendemos que a metáfora conceptual CORONAVÍRUS/COVID-19 É INIMIGO desencadeia na macro metáfora PANDEMIA É GUERRA, caracterizada, em nossa investigação, como a metáfora mais ampla.

Cumpre informar, ainda, que ao analisarmos essas expressões linguísticas, observamos que, muitas vezes, o vírus (coronavírus) é entendido como a doença que ele provoca (Covid19). Assim, entendemos que nessa relação sinonímica há, também, a atualização da metonímia VÍRUS PELA DOENÇA, evidenciando, portanto, o caso em que uma metonímia e uma metáfora coocorrem em uma mesma expressão linguística, ou seja, há o cruzamento ${ }^{6}$ de metáfora e metonímia.

Para o referencial teórico desta investigação, recorremos aos estudos de Lakoff e Johnson (2002 [1980]), os pressupostos da Teoria dos Modelos Cognitivos Idealizados (MCls) aventados por Lakoff (1987) e Feltes (2007).

\footnotetext{
4 Conforme convenção proposta por Lakoff e Johnson (2002 [1980]), as metáforas conceptuais são apresentadas em letras maiúsculas.

${ }_{5}$ Conforme exposto nos procedimentos metodológicos, para fins de investigação, abordamos esses dois termos, coronavírus e Covid-19, indistintamente quanto às suas definições uma vez que no gênero investigado os referidos termos são semanticamente abordados de forma semelhante na atual conjuntura.

6 De acordo com Barcelona (2003, p. 12), "isso acontece, a propósito, quando uma metonímia ocorre simultaneamente em uma mesma expressão linguística com um certo mapeamento metafórico, do qual aquela é conceptualmente independente".
} 


\section{$=$ TRAMA $=$}

No que tange à estrutura organizacional deste artigo, salientamos que ele está dividido da seguinte maneira: inicialmente, apresentamos uma breve discussão sobre a Teoria Contemporânea da Metáfora Conceptual, a partir dos estudos aventados por Lakoff e Johnson (2002 [1980]) e Lakoff (1987). Em um segundo momento, expomos o procedimento metodológico adotado que nos permitiu identificar as metáforas conceptuais, conforme Sardinha (2007), bem como todo processo de levantamento e coleta dos dados. Em seguida, apresentamos a análise das manchetes de notícias coletadas no Jornal Folha de São Paulo e no Jornal O Globo. Por fim, expomos as considerações finais, correlacionando as análises empreendidas e o aporte teórico no qual nos ancoramos.

\section{TEORIA COGNITIVA DA METÁFORA CONCEPTUAL}

Os estudos que refletem sobre as relações existentes entre o funcionamento da mente e nossas experiências corpóreas com o mundo se desenvolveram no âmbito do Cognitivismo, conforme Lakoff (1987). Essa relação se manifesta na forma como categorizamos o mundo e é teorizada através dos Modelos Cognitivos Idealizados (MCls).

Nessa perspectiva, Lakoff $(1987$, p. 6) destaca que não poderíamos de modo algum agir, fisicamente, socialmente e intelectualmente sem a capacidade de categorizar. A compreensão de como categorizamos é fundamental para se compreender como agimos e pensamos, e, por conseguinte, essencial para compreendermos o que nos torna humanos.

Cada vez que categorizamos alguma coisa, algumas propriedades são destacadas, enquanto outras são necessariamente ignoradas ou ocultadas. Para Lakoff e Johnson (2002 [1980], p. 266, grifo dos autores), "a categorização é uma forma natural de identificar um tipo de objeto ou de experiência iluminando certas propriedades, atenuando umas e até escondendo outras".

Acerca do fenômeno da categorização, Lakoff (1987) afirma que a categorização humana é, essencialmente, uma questão de experiência e de imaginação propondo uma divisão bipartite: a percepção, a atividade motora e a cultura de um lado; a metáfora, a metonímia e os esquemas de imagens de outro.

Ainda segundo autor, grande parte da categorização é automática e inconsciente, categorizamos pessoas, animais e objetos físicos, mas a maior parte das categorizações que fazemos são abstratas.

De acordo com os pressupostos lakoffianos, os MCls apresentam quatro tipos de princípios estruturadores: estruturas de imagem-esquemática; estruturas proposicionais; mapeamentos metonímicos e mapeamentos metafóricos que dão origem a cinco tipos de modelos cognitivos: esquema de imagens, proposicionais, metonímicos, metafóricos, simbólicos. Detalhamos, a seguir, em função dos objetivos de nossa investigação, os modelos proposicionais.

Os modelos cognitivos proposicionais caracterizam-se principalmente por apresentarem uma natureza objetivista, marcada pela ausência de mecanismos imaginativos, como metáfora, metonímia ou imagens mentais. São constituídos, estruturalmente, em termos de esquemas de imagem e seus traços característicos são evidenciados pelo conjunto de elementos utilizados no $\mathrm{MCl}$, que abrange tanto o nível mais básico (entidades, ações, estados, propriedades, etc.), até outros níveis de modelos cognitivos.

Lakoff (1987) classifica os modelos cognitivos proposicionais da seguinte forma: proposição simples, frame, cenário ou script, feixe de traços, taxonomia e categoria radial. Com base nos objetivos de nossa investigação, faremos uma breve caracterização sobre os modelos proposicionais do tipo frame. 


\section{$=$ TRAMA $=$}

Segundo Barreto (2011, p. 33), frames "podem ser entendidos, dentro do domínio da Linguística, como estruturas que representam conceitos, evidenciando uma cena ou uma situação abstrata, fazendo uso, algumas vezes, de palavras para facilitar a compreensão".

Podemos explicar esse tipo de modelo cognitivo com a categoria solteirão, discutida por Lakoff (1987). Essa categoria, segundo o autor, é usada para fazer referência a um homem adulto e não casado. Entretanto, esse termo não corresponde a todos os homens com essas características. Em nossa sociedade existem alguns homens não casados, com idade considerada "ideal" para casar, mas não se enquadram nessa categoria, como o Papa, por exemplo.

Lakoff (1987) explica que na realidade essa definição de solteirão está relacionada a um $\mathrm{MCl}$ definido numa sociedade humana que pressupõe casamentos tipicamente monogâmicos e uma idade apropriada para casar. Todavia, esse $\mathrm{MCl}$ não se ajusta ao mundo de forma precisa, apresenta diferentes níveis de semelhança uma vez que, conforme Ferrari (2011, p. 55), "trata-se de um modelo idealizado que, portanto, não considera a existência de padres, casais estáveis não casados, homossexuais, polígamos etc".

Em 1970, o linguista George Lakoff e o filósofo Mark Johnson conduziram de forma inovadora os estudos sobre metáfora e assim lançaram uma nova perspectiva para a compreensão da natureza e da estrutura do fenômeno metafórico. A publicação do livro Metaphors we live by, em 1980, consolidou uma nova visão sobre a metáfora estabelecendo a ruptura com a concepção clássica apresentada. Dessa forma, a metáfora deixa de ser relacionada apenas à ornamentação literária e poética e passa a ser compreendida como um aparato cognitivo e, por isso, exerce grande influência na nossa maneira de pensar, raciocinar e agir.

Nessa perspectiva, Lakoff e Johnson (2002[1980]) afirmam que as metáforas são atualizadas linguisticamente por expressões presentes no campo da cognição em que grande parte dos conceitos abstratos são entendidos metaforicamente. Consoante essa ideia, os autores demonstram que, para falar de um conceito abstrato como DISCUSSÃO, recorremos ao uso de expressões linguísticas que revelam a metáfora conceptual DISCUSSÃO É GUERRA. Segundo os autores, quando concebemos discussão em termos de guerra, entendemos como se estivéssemos em uma batalha. Nas palavras dos autores:

\footnotetext{
É importante perceber que não somente falamos sobre discussão em termos de guerra. Podemos realmente ganhar ou perder uma discussão. Vemos as pessoas com quem discutimos como um adversário. Atacamos suas posições e defendemos as nossas. Ganhamos e perdemos terreno. Planejamos e usamos estratégias. Se achamos uma posição indefensável, podemos abandoná-la e colocar-nos numa linha de ataque (LAKOFF; JOHNSON, 2002 [1980], p. 47, grifo dos autores).
}

Podemos atualizar a metáfora supracitada a partir de várias expressões, por exemplo: "Ele atacou todos os pontos fracos da minha argumentação", "Podemos abandoná-la e colocarmo-nos numa linha de ataque" e "Jamais ganhei uma discussão com ele".

Os referidos autores também afirmam que grande parte das ações executadas numa discussão são parcialmente estruturadas pelo conceito de guerra, já que alguns aspectos são destacados enquanto outros são encobertos: "Embora não haja uma batalha física há uma batalha verbal, que se reflete na estrutura de uma discussão - ataque defesa, contra-ataque, etc." (LAKOFF; JOHNSON, 2002[1980], p. 47).

Segundo os autores, as metáforas compreendem relações entre domínio fonte e domínio alvo. Para ilustrar a relação apresentada entre esses dois domínios, temos o exemplo da metáfora conceptual AMOR É UMA VIAGEM. Na análise desses domínios são selecionados 


\section{$=$ TRAMA $=$}

alguns aspectos que partem do domínio fonte, o conceito mais concreto (viagem), para o domínio alvo, o mais subjetivo e abstrato (amor). Vale ressaltar que, no mapeamento não há identificação total entre os conceitos metafóricos, alguns aspectos são iluminados, enquanto outros são ocultados. A partir do mapeamento relacionado à metáfora AMOR É UMA VIAGEM, podemos ter expressões linguísticas como: "Nosso casamento está indo bem", "Decidimos tomar caminhos diferentes", expressões linguísticas que atualizam a metáfora AMOR É UMA VIAGEM.

Lakoff e Johnson, em 1980, classificam as metáforas conceptuais em três categorias: estruturais, orientacionais, ontológicas. As estruturais são aquelas que estruturam metaforicamente um conceito em termos de outro. Nesse sentido, podemos afirmar que há uma estruturação nas maneiras pensar, raciocinar e agir. Um dos exemplos citados pelos autores para classificar esse tipo de metáfora é TEMPO É DINHEIRO, nessa relação metafórica tempo é compreendido como algo que podemos economizar, desperdiçar, gastar. Nessa direção, o conceito de tempo (abstrato) é estruturado metaforicamente como dinheiro, conceito mais concreto. A metáfora TEMPO É DINHEIRO pode ser atualizada por meio de expressões linguísticas como: "Você deve calcular bem o seu tempo", "Tenho investido muito tempo nela".

As metáforas orientacionais são caracterizadas por sua relação com as orientações espaciais com base em nossa experiência física e cultural: "para cima - para baixo", "dentro fora", "frente - atrás", "em cima de - fora de", "fundo-raso", "central - periférico". Para fins de exemplificação, temos FELIZ É PARA CIMA e TRISTE É PARA BAIXO, que são atualizadas em expressões linguísticas como "Meu astral subiu" e "Estou deprimido".

As metáforas ontológicas têm como base nossas experiências referentes a eventos abstratos como atividades, ideias, emoções, etc., entendidos em termos de entidades e substância, coisas ou seres. Como exemplo, podemos observar a metáfora ontológica MENTE É UMA MÁQUINA, em que a mente é experienciada como algo que pode estar "ligado/desligado", "ter um nível de eficiência", etc., conforme as seguintes expressões linguísticas atualizam "A minha mente simplesmente não está funcionando hoje", "Estou um pouco enferrujado hoje".

Lakoff e Johnson (2003), na obra Metaphors we live by ${ }^{7}$, especificamente no posfácio, revisitam a Teoria da Metáfora Conceptual. Após novos estudos, os autores propõem reformulações acerca de alguns aspectos da visão cognitiva da metáfora abandonando a classificação instituída por eles em 1980 (estruturais, orientacionais e ontológicas), e afirmam ser possível analisar metáforas sem considerar essa classificação.

\section{METODOLOGIA}

Os textos que constituem o corpus desta pesquisa são manchetes de notícias coletadas em dois jornais de circulação nacional, Folha de São Paulo e O Globo. A relevância das notícias, tendo como objeto os jornais supracitados, está atrelada ao fato de se tratar de dois periódicos de maior circulação e formação de opinião no Brasil. É importante frisar que para verificar se há recorrência de metáforas conceptuais nos corpora do gênero estudado, não recorremos ao corpo da notícia jornalística, a expressão linguística atualizadora foi extraída exclusivamente do título que compõe a notícia.

\footnotetext{
${ }^{7}$ A divisão das metáforas em três tipos - orientacionais, ontológicas e estruturais - era artificial. Todas as metáforas são estruturais (no sentido de que elas mapeiam as estruturas para outras estruturas); todas são ontológicas (no sentido de que elas criam domínios-alvo como entidades); e muitas são orientacionais (no sentido de que elas mapeiam esquemas-imagem orientacionais) (LAKOFF; JOHNSON, 2003, p. 264, tradução nossa).
} 


\section{$=$ TRAMA $=$}

Cumpre observar, ainda, que a coleta dos dados consistiu de duas etapas: a primeira correspondeu à análise de notícias extraídas do Jornal Folha de São Paulo, veiculadas no site, https://www.folha.uol.com.br/, do referido jornal entre os dias 1 e 30 de abril de 2020; a segunda, por sua vez, compilou notícias analisadas no Jornal O Globo, em sua versão on-line, https://oglobo.globo.com/, veiculadas entre os dias 1 e 31 de julho de 2020. Ressalte-se que a escolha dos períodos advém do interesse em verificar se há predomínio de um determinado tipo de metáfora conceptual nos corpora do gênero investigado, em periódicos diferentes, desde o período "inicial" da pandemia do coronavírus no Brasil até o mês de julho de 2020. A quantidade de expressões linguísticas atualizadoras da metáfora CORONAVÍRUS/COVID-19 É INIMIGO, encontradas nos dois corpora obedece à seguinte proporção: 51 ocorrências no Jornal Folha de São Paulo e 39 ocorrências no Jornal O Globo.

Para efeitos de identificação de metáforas conceptuais, recorremos ao procedimento metodológico proposto por Sardinha (2007, p. 140), método leitura, para quem "este método consiste em encontrar metáfora pela leitura de materiais escritos." A coleta dos dados nos referidos jornais ocorreu por meio da utilização de uma ferramenta on-line, na qual digitamos as palavras coronavírus/Covid-19 com o intuito de fazer um levantamento de expressões linguísticas decorrentes desses termos em manchetes de notícias. Cumpre informar, ainda, que, conforme exposto na introdução deste trabalho, interpretamos os termos coronavírus e Covid-19 indistintamente, ou seja, como sendo semelhantes uma vez que nas expressões linguísticas sob análise observamos uma relação sinonímica na qual o vírus (coronavírus), muitas vezes, é entendido como a doença que ele provoca (Covid-19). Nesse sentido, entendemos que na base das expressões em tela há, também, a metonímia VÍRUS PELA DOENÇA, evidenciando, portanto, o cruzamento de metáfora e metonímia numa mesma expressão linguística. Conforme autoridades de saúde, resumidamente, Covid-19 é a doença, Sar-CoV-2 é o vírus e coronavírus ${ }^{8}$ é a família de vírus a que ele pertence.

A metodologia de pesquisa utilizada é de natureza qualitativa, uma vez que nosso intuito maior foi a análise interpretativa das expressões linguísticas atualizadoras de metáforas referentes ao tema/assunto coronavírus/Covid-19. Recorremos, também, à concepção de metáfora conceptual abordada nos estudos de Lakoff e Johnson (2002[1980]), os pressupostos da Teoria dos Modelos Cognitivos Idealizados aventados por Lakoff (1987) e Feltes (2007) que nos permitiu descrever e identificar as expressões linguísticas metafóricas e a metáfora conceptual subjacente.

No intuito de facilitar a leitura dos dados, destacamos em negrito a expressão atualizadora da metáfora conceptual sob análise. Cumpre informar, também, que conforme convenção estabelecida por Lakoff e Johnson (2002 [1980]), a metáfora conceptual foi apresentada em letras maiúsculas. Para fins de identificação, convencionamos utilizar as siglas JFSP e JOG para nos referirmos, respectivamente, aos jornais Folha de São Paulo e O Globo, além de outras três informações: dia, mês e ano em que foi veiculada a notícia.

\section{ANÁLISE DOS DADOS}

Apresentaremos, a seguir, o levantamento e a análise dos dados sobre a conceptualização dos termos amplamente citados nas manchetes do Jornal Folha de São Paulo, que perfaz um total de 51 ocorrências. Ao analisarmos os termos coronavírus/Covid-19,

\footnotetext{
${ }^{8}$ De acordo com site Guia do Estudante, a Organização Mundial da Saúde (OMS) estabeleceu que deverá ser chamada de Covid-19 a doença respiratória provocada pela infecção do novo coronavírus. O termo Covid-19 teve sua origem nas palavras "corona", "vírus" e "doença" com indicação do ano em que surgiu (2019).
} 


\section{$=$ TRAMA $=$}

constatamos que eles são compreendidos metaforicamente, em termos de guerra, como um inimigo em potencial.

\begin{tabular}{|l|}
\hline Contra coronavírus, Kim Jong-un deve bloquear Coreia do Norte por ao menos um ano. (JFSP - 01.04.2020) \\
\hline Elas sobreviveram à gripe espanhola e ao Holocausto; agora, enfrentam o coronavírus. (JFSP - 02.04.2020) \\
\hline Contágio em sauna pública na China indica que coronavírus resiste a alta umidade e calor. (JFSP - \\
$02.04 .2020)$ \\
\hline Após chuvas, moradores do RJ vivem isolamento contra coronavírus em casas interditadas. (JFSP - \\
02.04.2020) \\
\hline Justiça do Trabalho já destinou R\$ 80 milhões a ações contra o coronavírus. (JFSP - 02.04.2020) \\
\hline Para conter Covid-19, saúde precisaria de oito vezes mais que valor pedido, diz conselho. (JFSP - \\
02.04.2020) \\
\hline Covid-19 vai vencendo a primeira batalha, (JFSP - 03.04.2020) \\
\hline Base digital de Bolsonaro vê autoritarismo nas medidas de combate ao coronavírus. (JFSP - 03.04.2020) \\
\hline Coronavírus obriga a evacuação de porta-aviões americano no Pacífico. (JFSP - 03.04.2020) \\
\hline Ministério da Saúde cria cadastro de profissionais da saúde para ajudar no combate ao coronavírus. (JFSP \\
\hline
\end{tabular} $-03.04 .2020$

Maia diz que Bolsonaro não tem coragem de demitir Mandetta e mudar política contra coronavírus. (JFSP 04.04.2020)

Câmara aprova PEC do Orçamento de guerra contra coronavírus. (JFSP - 04.04.2020)

Regina Duarte posta, e depois apaga, chamado de jejum religioso contra coronavírus. (JFSP - 04.04.2020)

Coronavírus devasta a indústria cultural nos EUA, que pede 'Plano Marshall'. (JFSP - 04.04.2020)

Médico, premiê da Irlanda vai trabalhar um dia por semana no combate ao coronavírus. (JFSP - 06.04.2020)

Brasileiros deixam sapatos na porta de casa para se proteger do coronavírus. (JFSP - 06.04.2020)

Assim como Bolsonaro, seus apoiadores não temem o coronavírus. (JFSP - 06.04.2020)

Japão anuncia estímulo de 20\% do PIB em combate ao coronavírus. (JFSP - 07.04.2020)

$28 \%$ dos brasileiros não fazem isolamento contra coronavírus, diz Datafolha. (JFSP - 07.04.2020)

Lady Gaga comanda show global com astros para combate ao coronavírus. (JFSP - 07.04.2020)

Juiz bloqueia recursos do fundo eleitoral e libera uso para combate ao coronavírus. (JFSP - 08.04.2020)

Contra coronavírus, cidades do litoral paulista vão barrar a entrada de turistas no feriado de Páscoa. (JFSP $-09.04 .2020)$

Gestão Witzel impõe sigilo em documentos de contratações emergenciais de $\mathrm{R} \$ 1$ bi contra coronavírus. (JFSP - 09.04.2020)

Motoristas de van escolar de SP passam a ajudar equipes de saúde no combate ao coronavírus. (JFSP 10.04.2020)

Bancos que lucraram bilhões deveriam pagar bilhões para combater o coronavírus. (JFSP - 10.04.2020)

Apple e Google vão criar tecnologia de rastreamento de contatos para combater coronavírus. (JFSP 11.04.2020)

Sem proteção, vendedores desafiam Covid-19 e segurança reforçada em trens da CPTM. (JFSP 13.04.2020)

Itaú prepara doação de $\mathrm{R} \$ 1$ bilhão para combater coronavírus. (FSP - 13.04.2020)

Coronavírus gera mais temor nos EUA do que terrorismo e ataques nucleares, diz pesquisa. (JFSP 14.04.2020)

Doação bilionária do Itaú para combater coronavírus deve ampliar testes e equipamentos no país. (JFSP 14.04.2020)

Maia cobra fundo de bancos para apoiar ações contra coronavírus. (JFSP - 14.04.2020)

Justiça federal libera $R \$ 120$ milhões de acordo com a Samarco para combate ao coronavírus. (JFSP 14.04.2020)

'Destemida', enfermeira da $2^{\mathrm{a}}$ Guerra venceu coronavírus com fé, diz filha. (JFSP - 14.04.2020)

Mandetta mostra que Bolsonaro é o inimigo do combate ao coronavírus. (JFSP - 16.04.2020)

Formulador da estratégia de combate ao coronavírus pede demissão do Ministério da Saúde. (JFSP 16.04.2020)

Empresários temem ser obrigados a emprestar dinheiro para combater coronavírus. (JFSP - 18.04.2020)

Doria coincide em discurso com Cuomo, de NY, mas tem estratégia mais leve contra coronavírus. (JFSP 18.04.2020)

Coronavírus já matou mais de 150 mil pessoas no mundo em cerca de três meses. (JFSP - 18.04.2020)

Como vai ser o primeiro programa nacional de caça ao coronavírus. (JFSP - 19.04.2020)

'Combate à Covid-19 criará sociedade rastreada como nunca', diz pesquisadora. (JFSP - 19.04.2020)

Somos parte da batalha contra a Covid-19. (JFSP - 24.04.2020)

Revista médica americana elenca seis passos para 'esmagar' coronavírus em dez semanas. J(FSP 25.04.2020) 


\section{$=\mathrm{T} R A M A=$}

Na linha de frente contra o coronavírus, tem que ter sangue no olho, diz enfermeira alvo de fake News. (JFSP $-28.04 .2020)$

Novo número 2 do Ministério da Saúde defende ações específicas por região contra Covid. (JFSP 28.04.2020)

Kim Jong-un pode estar ausente para se proteger do coronavírus, diz ministro da Coreia do Su. (JFSP 29.04.2020)

Médica da linha de frente contra coronavírus comete suicídio nos EUA. (JFSP - 29.04.2020)

Apoio a isolamento social amplo para conter o coronavírus cai 8 pontos, mostra Datafolha. (JFSP 29.04.2020)

Aos 91 anos, alfaiate de Mirandópolis combate coronavírus produzindo máscaras para doação. (JFSP 29.04.2020)

Medidas duras contra Covid-19 no Peru esbarram em problemas sociais. (JFSP - 29.04.2020)

Trump critica combate do Brasil à Covid-19 e volta a cogitar restrição de voos do país. (JFSP - 29.04.2020)

Sob críticas, Nicarágua anuncia medidas tímidas contra coronavírus. (JFSP - 29.04.2020)

Segundo Lakoff e Johnson (2002 [1980]), ao conceptualizarmos nossas experiências como entidades ou substâncias, podemos, parcialmente, selecionar essas experiências e podemos referir-nos a elas, categorizá-las, agrupá-las, quantificá-las e, consequentemente, raciocinar sobre elas. Assim, nos recortes supracitados, constatamos os termos coronavírus/Covid-19 estruturados como um inimigo que devemos combater: "estratégia de combate ao coronavírus", desafiar: "vendedores desafiam Covid-19", enfrentar: "enfrentam o coronavírus", ser contra: "ações contra o coronavírus", vencer: "enfermeira da $2^{a}$ Guerra venceu coronavírus", caçar: "caça ao coronavírus", esmagar: "seis passos para 'esmagar' coronavírus", nos proteger: "se proteger do coronavírus", conter: "conter o coronavírus". Desse modo, temos a atualização da metáfora ontológica CORONAVÍRUS/COVID-19 É INIMIGO que exibe uma recorrência expressiva nas notícias investigadas.

Nessas expressões, verificamos que aspectos característicos do domínio fonte inimigo foram amplamente utilizados para estruturar o conceito coronavirus/Covid-19. Desse modo, conviver ou estar suscetível a contrair o vírus (coronavírus) e, consequentemente, estar com a doença (Covid-19) corresponde a uma guerra contra esse inimigo, os adversários da guerra somos todos nós, pessoas que vivenciam o desafio diário de se proteger do vírus (Sar-CoV-2) classificado pelas autoridades de saúde como altamente contagioso e letal. É importante ressaltar, ainda, que "ser adversário" é estar em estado de guerra e suscita estabelecer estratégias, daí a necessidade de combater, desafiar, enfrentar, vencer, nos proteger. É assim que o coronavírus/Covid-19 é experienciado atualmente em nossa sociedade: um inimigo em potencial. Nesse sentido, entendemos que as manchetes de notícias analisadas sugerem, metaforicamente, a criação de um espaço de combate ou luta onde devem ser criadas estratégias para vencer e/ou combater o coronavírus/Covid-19.

Cumpre observar, ainda, que no mapeamento entre os domínios da metáfora supracitada, apenas alguns elementos do domínio fonte (inimigo) foram conceptualizados parcialmente para o domínio alvo (coronavírus/Covid-19). Ressalte-se que a confirmação de tal parcialidade na conceptualização metafórica é prevista nos pressupostos dos autores Lakoff e Johnson (2002 [1980], p. 48, grifo dos autores), na Teoria da Metáfora Conceptual: "A essência da metáfora é compreender e experienciar uma coisa em termos de outra.", neste caso o compreender coronavírus/Covid-19 como inimigo. Essa compreensão de inimigo relacionada aos termos coronavírus/Covid-19 nas expressões linguísticas sob análise, foi metaforicamente construída e estruturada a partir de nossas experiências corpóreas provenientes de nossa relação com o mundo, conforme preceituam Lakoff e Johnson (2002 [1980]).

Ainda segundo os autores, cada vez que categorizamos alguma coisa, certas propriedades são destacadas, enquanto outras necessariamente são ocultadas. Nesse sentido, verificamos que outros aspectos do domínio fonte (guerra) foram encobertos/desviados, como 


\section{$=\mathrm{T} R A M A=$}

violência e sangue, confirmando, portanto, que os termos coronavírus/Covid-19 foram parcialmente estruturados, compreendidos e tratados em termos de guerra, desencadeando, desse modo, na metáfora PANDEMIA É GUERRA, conforme exposto na introdução deste trabalho.

Prosseguimos nossas análises dos resultados referentes à investigação da ocorrência de expressões linguísticas atualizadoras da metáfora conceptual CORONAVÍRUS/COVID-19 É INIMIGO no jornal de circulação nacional O Globo, que constituiu um dos corpora desse estudo. Conforme expusemos em nossa metodologia, as notícias que compuseram essa etapa da investigação foram veiculadas no site do referido jornal entre os dias 1 e 31 de julho de 2020.

Apresentaremos agora os excertos referentes às expressões linguísticas encontradas em manchetes de notícias do Jornal O Globo sobre o coronavírus/Covid-19, que perfazem um total de 39 ocorrências atualizadoras da metáfora conceptual CORONAVÍRUS/COVID-19 É INIMIGO.

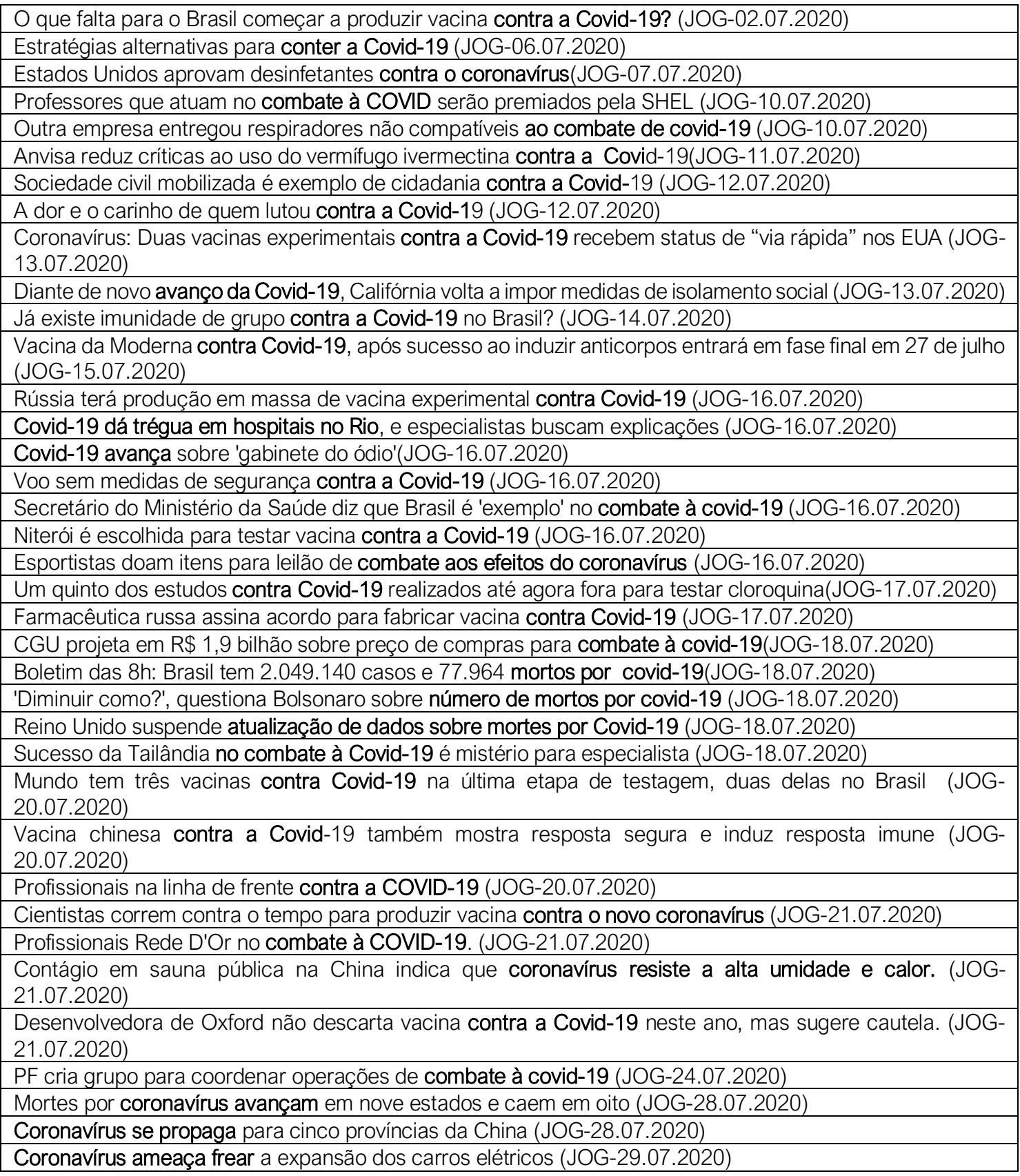




\section{$=\mathrm{T} R A M A=$}

Senado do EUA e do Brasil fazem tabelinha contra coronavírus (JOG-31.07.2020)

Novo coronavírus é uma metralhadora giratória (JOG-31.07.2020)

No segundo corpus investigado também se verifica a ocorrência da metáfora conceptual CORONAVÍRUS/COVID-19 É INIMIGO. Os excertos sob análise evidenciam a categorização do termo coronavírus/Covid-19 como um inimigo que devemos: ser contra: "vacina contra a Covid-19", conter: "conter a Covid-19", combater: "combate à COVID"; um inimigo que avança: "avanço da Covid-19", resiste: "coronavírus resiste a alta umidade e calor", se propaga: "Coronavírus se propaga".

A partir das expressões utilizadas, é possível constatar que, ao experienciar metaforicamente os termos coronavírus/Covid-19 como um inimigo, o locutor mobiliza o leitor a adotar "estratégias de oposição ao inimigo", por exemplo: combater, conter. Ressalte-se que, mais uma vez, os termos em questão foram parcialmente conceptualizados em termos de guerra. Nesse sentido, sugerimos que tal conceptualização advém de nossas experiências cotidianas de lidar com o inimigo. Isso explica o fato de, nas manchetes das notícias investigadas, o coronavírus/Covid-19, enquanto algo metaforicamente construído sob o domínio experiencial de guerra, precise ser contido, combatido.

Cumpre observar, também, que o mapeamento ocorre a partir de um termo abstrato (coronavírus/Covid-19), o domínio alvo, compreendido como inimigo, o domínio fonte, através das experiências e vivências que se pode ter concretamente no cotidiano. Desse modo, o mapeamento foi metaforicamente construído a partir de nossas experiências mais concretas para conceptualizar uma mais abstrata.

Ao cotejarmos os dados coletados dos corpora, verificamos que há um maior número de ocorrências de duas expressões linguísticas: "contra o coronavírus/Covid-19" e "combate ao coronavírus/Covid-19". Embora as outras expressões linguísticas encontradas também corroborem o "ser inimigo" que vivenciamos com o coronavírus/Covid-19 em nossa sociedade atualmente, já que os itens lexicais circunscritos nas expressões linguísticas pertencem também ao campo semântico das estratégias e procedimentos utilizados contra inimigos: conter, avançar, enfrentar, proteger, resistir, vencer, etc.

É importante ressaltar, ainda, que o frame ${ }^{9}$ de inimigo construído nos excertos sob análise não nos causa estranhamento, ao contrário, ele é amplamente compreendido. Acreditamos que isso se deve ao fato de estarmos constantemente expostos a vários eventos desse tipo, como por exemplo, campanhas veiculadas pelo Ministério da Saúde sobre: a amamentação: "Apoie a amamentação. Proteger o futuro é papel de todos."; contra a dengue: "Combater o mosquito é com você, comigo e com todo mundo."; Aids: "Dia mundial de luta contra a Aids." Sendo assim, embora não estejamos experienciando atualmente uma inimizade de fato, mapeamos parcialmente doenças e agentes patológicos citados nessas campanhas em termos de um inimigo, como algo que devemos proteger, combater, lutar contra, etc. É o que acontece com a metáfora em questão, ao conceptualizarmos o coronavírus/Covid-19 em termos de inimigo, agimos e pensamos como oponentes.

\section{CONSIDERAÇÕES FINAIS}

Neste trabalho, investigamos a metáfora conceptual CORONAVÍRUS/COVID-19 É INIMIGO atualizada por diferentes expressões linguísticas circunscritas no gênero discursivo notícia. Recorremos, especificamente, às manchetes jornalísticas, objeto de nossa

\footnotetext{
9 De acordo Ferrari (2011, p. 50), "o termo frame designa um sistema estruturado de conhecimento, armazenado na memória de longo prazo e organizado a partir da esquematização da experiência."
} 


\section{$=\mathrm{T} R A M A=$}

investigação, em que verificamos o uso recorrente da categorização dos conceitos coronavírus/Covid-19 atualizados sob a perspectiva dos modelos cognitivos metafóricos.

$\mathrm{Na}$ análise dos dados, a conceptualização metafórica dos conceitos coronavírus/Covid19 mostrou como aspectos centrais do domínio fonte GUERRA (combate, desafio, enfrentamento, resistência, avanço, proteção, etc.) foram apropriados para compreender metaforicamente o domínio alvo. Desse modo, compreendemos que a ocorrência sistemática da metáfora CORONAVÍRUS/COVID-19 É INIMIGO nos autoriza a fazer a inferência da existência da metáfora mais ampla PANDEMIA É GUERRA.

No que diz respeito à análise empreendida, constatamos a ocorrência de 51 expressões linguísticas metafóricas em manchetes do Jornal Folha de São Paulo, enquanto que, no Jornal O Globo, verificamos a recorrência de 39 manifestações linguísticas, perfazendo, desse modo, um total de 90 expressões linguístico-discursivas atualizadoras da metáfora conceptual CORONAVÍRUS/COVID-19 É INIMIGO, um número bem expressivo de ocorrências nos corpora investigados. Também pudemos verificar, nas análises arroladas, que alguns aspectos do domínio fonte inimigo foram mapeados parcialmente para a compreensão do domínio alvo coronavírus/Covid-19, a partir dos seguintes excertos: combater: "estratégia de combate à Covid-19", enfrentar: "enfrentam o coronavírus", vencer: "enfermeira da $2^{\mathrm{a}}$ Guerra venceu coronavírus", um inimigo que avança: "avanço da Covid-19", resiste: "coronavírus resiste a alta umidade e calor", conter: "conter o coronavírus", esmagar: "seis passos para 'esmagar' o coronavírus", nos proteger: "se proteger do coronavírus".

Com base em nossas análises, entendemos que ao se deparar com as expressões linguísticas motivadas por essa metáfora, o leitor é motivado, discursivamente, a se mobilizar adotando "estratégias de guerra" como se proteger, combater, enfrentar tal inimigo.

De modo geral, constatamos que os conceitos analisados, ao serem categorizados metaforicamente, são experienciados atualmente em nossa sociedade como um inimigo em potencial. Nesse sentido, verificamos, metaforicamente, a criação de um espaço de combate ou luta nas manchetes de notícias analisadas, que sugerem a criação de estratégias para vencer e/ou combater o coronavírus/Covid-19. Ressaltamos que este trabalho pode servir como ponto de partida para futuras pesquisas que visem investigar os termos coronavírus/Covid-19, bem como evidenciamos a relevância desta investigação por meio de dados que tratam de um tema atual em nossa sociedade no campo da Semântica Cognitiva.

Os dados da pesquisa revelam uma amostragem da ocorrência da metáfora conceptual CORONAVÍRUS/COVID-19 É INIMIGO, tendo em vista que foi mapeado um curto período de tempo, correspondente a 01 de abril a 31 de julho de 2020, revelando-nos, desse modo, a limitação desta investigação.

Por fim, ressaltamos que a análise empreendida nesta investigação se configura como uma possibilidade, podendo ser direcionada a outros desdobramentos e interpretações.

\section{REFERÊNCIAS}

BARRETO, D. R. S. Conceitualização de educação à luz da teoria dos modelos cognitivos idealizados: percorrendo veredas entre mente e linguagem dos alunos da educação básica. 2011, 141 p. Dissertação (Mestrado em Linguística). Universidade Federal do Ceará, Fortaleza, 2011.

CARVALHO, S. R. P. de. As metáforas conceptuais nas homilias do Papa Francisco. 2017, 80p. Dissertação (Mestrado em Linguística). Universidade Federal da Paraíba, João Pessoa, 2017.

FELTES, Heloísa Pedroso de Moraes. Semântica Cognitiva: ilhas, pontes e teias. Porto Alegre: Edipucrs, 2007.

FERRARI, Lilian. Introdução à Linguística Cognitiva. São Paulo: Contexto, 2011.

FOLHA DE SÃO PAULO. Disponível em: <https://www.folha.uol.com.br/> Acesso em: jul.- ago. 2020. GUIA DO ESTUDANTE. Disponível em: <https://guiadoestudante.abril.com.br/estudo/qual-e-a-diferencaentre-coronavirus-covid-19-e-sars-cov-2-entenda/> Acesso em: 2 jul. 2020. 
LAKOFF, G. Women, Fire and Dangerous Things: What categories reveal about the mind. Chicago: The University of Chicago Press, 1987.

LAKOFF, G.; JOHNSON, M. Metaphors we live by. Chicago: University of Chicago Press, 2003.

LAKOFF, G.; JOHNSON, M. Metáforas da vida cotidiana. (Coordenação da tradução Mara Sophia Zanotto) Campinas, SP: Mercado de Letras; São Paulo: EDU, 2002 [1980].

MINISTÉRIO DA SAÚDE. Disponível em: <https://www.gov.br/saude/pt-br/campanhas-da-saude/2020>

Acesso em: 2 jul. 2020.

O GLOBO. Disponível em: <https://oglobo.globo.com/> Acesso em: jul.- ago. 2020.

SARDINHA, T. B. Metáfora. São Paulo: Parábola, 2007.

Recebido em 30-10-2020

Revisões requeridas em 24-11-2020

Aceito em 13-12-2020 